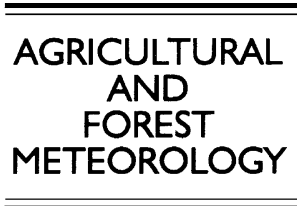

Agricultural and Forest Meteorology 111 (2002) 93-108

www.elsevier.com/locate/agrformet

\title{
Estimation of the three-dimensional aerodynamic structure of a green ash shelterbelt ${ }^{\text {th }}$
}

\author{
X.H. Zhou ${ }^{\text {a,* }}$, J.R. Brandle ${ }^{\text {a }}$, E.S. Takle ${ }^{\text {b,c }}$, C.W. Mize ${ }^{\text {d }}$ \\ a School of Natural Resource Sciences, University of Nebraska, Lincoln, NE 68583-0814, USA \\ ${ }^{\mathrm{b}}$ Department of Geological and Atmospheric Sciences, Iowa State University, Ames, IA 50011, USA \\ ${ }^{c}$ Department of Agronomy, Iowa State University, Ames, IA 50011, USA \\ ${ }^{\mathrm{d}}$ Forestry Department, Iowa State University, Ames, IA 50011, USA
}

Received 2 April 2001; received in revised form 14 February 2002; accepted 18 February 2002

\begin{abstract}
The three-dimensional aerodynamic structure of a tree shelterbelt is described by two structural descriptors: vegetative surface area density (vegetative surface area per unit canopy volume) and cubic density (vegetative volume per unit canopy volume). Based on destructive measurements, estimates of both descriptors for a two-row 31-year-old green ash (Fraxinus pennsylvanica Marsh.) shelterbelt are developed. In order to estimate the structural descriptors in three dimensions based on data measured in two dimensions, equations to predict vegetative surface area and volume, their marginal distribution with height, and their marginal distribution across width at a given height are derived for each tree component: trunk, branches, leaves and seeds. The procedure to use these equations to estimate the structure of the green ash shelterbelt either in three dimensions or in the width and height dimensions is demonstrated. The estimated structure can be used to test current models of turbulence through a tree shelterbelt under a field conditions, and to simulate the wind fields as influenced by the actual structure of a tree shelterbelt. The developed equation can be used to generate the three-dimensional structure of a shelterbelt with a design similar to the sampled shelterbelts or a shelterbelt of green ash mixed with other species similar to those in the sampled shelterbelts. Thus, the boundary-layer flows as influenced by the overall structure of tree shelterbelts with different designs can be numerically simulated. These simulated results can provide guidance for shelterbelt design. () 2002 Elsevier Science B.V. All rights reserved.
\end{abstract}

Keywords: Beta distribution; Cubic density; Cubic porosity; Vegetative surface area density; Windbreak(s)

\section{Introduction}

Shelterbelts are widely used to reduce wind speed and alter wind fields (Brandle et al., 1988). The aerodynamic influence of a particular shelterbelt on wind

\footnotetext{
is Published as Journal Series No. 13298 of the Agricultural Research Division, University of Nebraska.

* Corresponding author. Tel.: +1-402-472-6639;

fax: +1-402-472-2964.

E-mail address: xzhou@unlserve.unl.edu (X.H. Zhou).
}

speed, turbulent stress and pressure is dependent on its structure (Radke and Hagstrom, 1974; Wilson, 1987). Wind fields around a shelterbelt can be predicted by associating its aerodynamic influence with its structure. The more complex the shelterbelt structure, the more difficult it is to accurately associate the flow fields with its structure (Heisler and DeWalle, 1988).

When the barrier is a fence with a minimal width dimension, optical porosity, defined as the percentage of open space, has been used successfully to parameterize the drag force term in the equations of motion 
and to predict boundary-layer flows near the fence (Hagen et al., 1981; Wilson, 1985). In the case of a tree shelterbelt, its complex three-dimensional (3D) structure makes this simple representation inadequate to describe the details of the structure.

Shelterbelts with similar internal structural components but different external characteristics of height, width and cross-sectional shape exhibit very different aerodynamic influences on the wind fields (Woodruff and Zingg, 1953; Tabler and Veal, 1971; Cao et al., 1981). The geometric shapes of individual elements and open spaces between them also influence the flow fields close to the barrier (Gandemer, 1979; Perera, 1981). The surfaces of a canopy absorb momentum from and exert stress on air flow (Thom, 1971; Holland et al., 1991a,b). If the canopy of a tree shelterbelt is considered as a porous medium, then the drag force of a shelterbelt canopy on air flow is determined not only by its surface area but also by its volume (Scheidegger, 1974; Coulson et al., 1978). The spatial arrangement of the vegetative surface area in a shelterbelt canopy determines the distribution of momentum sinks and shear stress sources. Furthermore, as air diverges at the locations where the density of solid materials is high and converges at the locations where it is low, the spatial arrangement of the solid elements and open spaces determines the divergence and convergence of air flow within and around a shelterbelt canopy.

To accommodate all structural components of a shelterbelt, Brandle et al. (2002) defined the aerodynamic structure of a tree shelterbelt in three dimensions by its external characteristics of height, width and cross-sectional shape, by the internal amount and arrangement of vegetative surface area and volume within its canopy, and by the geometric shape of individual vegetative elements. Accordingly, vegetative surface area density (vegetative surface area per unit canopy volume) and cubic density (vegetative volume per unit canopy volume) were suggested as structural descriptors of choice for the overall 3D aerodynamic structure of a shelterbelt. Expressed as spatial functions, both can describe the amount and arrangement of vegetative surface area and volume within a shelterbelt canopy. Because both spatial functions would be continuously zero outside their domain boundaries, they also can indicate the external shelterbelt characteristics of height, width and cross-sectional shape. Furthermore, because plant elements with different geometric shapes have different surface volume ratios, spatial functions of vegetative surface area density and cubic density are capable of reflecting the geometric shape of individual elements.

As yet, neither function has been defined based on measured data. The actual 3D structure of a shelterbelt has never been used to numerically predict its aerodynamic influence. In order to undertake and test a numerical investigation of the aerodynamic influence of a shelterbelt, a method to estimate both functions is required. This paper presents a method to estimate the vegetative surface area density and cubic density of a green ash (Fraxinus pennsylvanica Marsh.) shelterbelt in three dimensions using equations whose parameters can be estimated based on the data measured in two dimensions.

\section{Working functions of vegetative surface area density and cubic density}

The numerical method to solve the turbulence model simulating the boundary-layer flows near a shelterbelt and within or above a forest canopy subdivides the working domain into an array of discrete grid cells (Wang and Takle, 1996; Lee, 2000). Therefore, the structural description of the shelterbelt requires estimates of both structural descriptors for each grid cell (see Fig. 1).

It is desirable that both descriptors be estimated using easily measured parameters, such as DBH (diameter at breast height of $1.37 \mathrm{~m}$ ) and height. Therefore, vegetative surface area density and cubic density need to be defined as functions in the form $S_{\mathrm{AD}}(D, h, x, y$, $z)$ and $\beta_{\mathrm{C}}(D, h, x, y, z)$, where $D$ represents $\mathrm{DBH} ; h$ is the tree height; and $x, y$, and $z$ are the spatial coordinates across width, along length and with height, respectively. It is difficult to define these two functions, because vegetative surface area and volume are not easy to measure in three dimensions. However, both are more easily measured layer by layer with height or section by section across width within a layer as shown in Fig. 1. If both functions are expressed in terms of equations whose parameters can be estimated using the data measured in this way, they can be defined based on field measurements. The lower the resolution of the grid cells, the easier it is to express both 
(A)

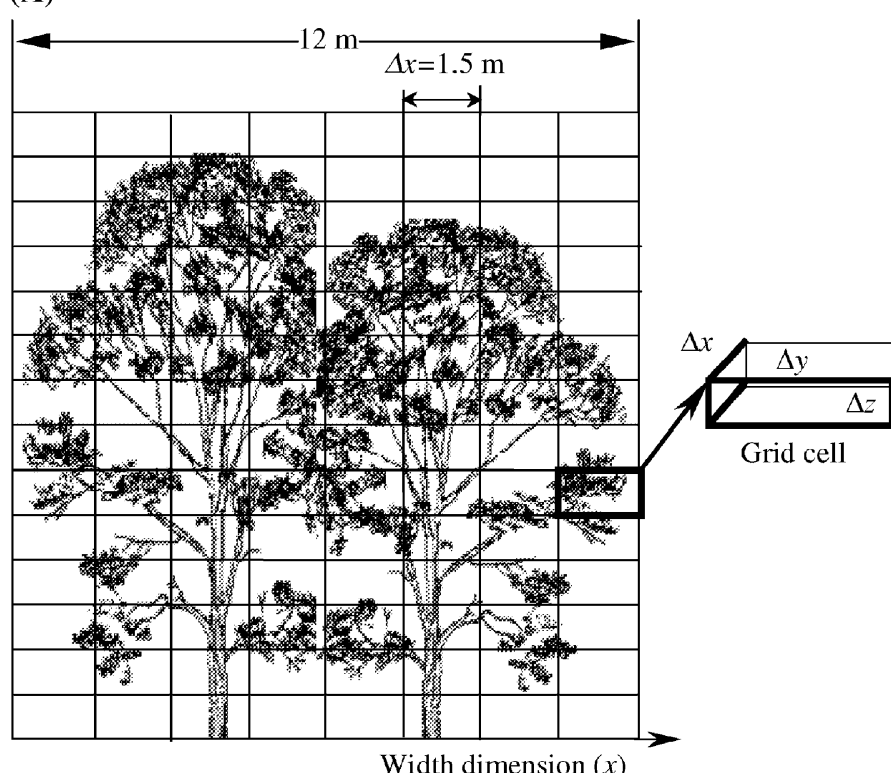

Width dimension $(x)$

(B)

Fig. 1. Cross-sectional view (A) and front row side view (B) of a green ash shelterbelt as an array of discrete grid cells. 
functions. The degree of resolution is determined by the size of the grid cells.

The grid cell sizes used by Wang and Takle (1995-1997) in their simulations provide guidance. Assuming that vegetative surface area of a shelterbelt is uniformly distributed along its length, they divided their hypothetical shelterbelts into increments of 0.1-0.5 times of shelterbelt height across the width dimension $(x)$ and 0.1 times of shelterbelt height with the height dimension $(z)$. If variability in shelterbelt structure along the length dimension $(y)$ is to be considered, the length dimension also must be subdivided. The distance between adjacent trees within a row in a shelterbelt can be an increment along the length dimension because it is small relative to shelterbelt length. Accordingly, the size of grid cells is suggested as: width, $\Delta x \leq 0.5$ times of shelterbelt height; length, $\Delta y=$ distance between adjacent trees within a row; and height, $\Delta z \leq 0.1$ times of shelterbelt height.

We used this resolution to develop a working function for estimating the vegetative surface area density in each grid cell centered at $(x, y, z)$ :

$$
\begin{aligned}
S_{A D}(D, h, x, y, z) & \\
= & \frac{1}{\Delta x \Delta y \Delta z} \sum_{i=1}^{4} S_{i}(D, h)\left[\int_{z-0.5 \Delta z}^{z+0.5 \Delta z} \psi_{S_{i}}\left(z^{\prime}\right) \mathrm{d} z^{\prime}\right] \\
& \times\left[\frac{1}{\Delta z} \int_{z-0.5 \Delta z}^{z+0.5 \Delta z} \int_{x-0.5 \Delta x}^{x+0.5 \Delta x} \varphi_{S_{i}}\left(x^{\prime} \mid z^{\prime}\right) \mathrm{d} x^{\prime} \mathrm{d} z^{\prime}\right]
\end{aligned}
$$

where subscript $i$ represents tree components: trunk, branches, leaves and seeds for $i=1,2,3$, and 4, respectively; $S_{i}(D, h)$ is the surface area of tree component $i$ for an entire tree; $\psi_{S_{i}}(z)$ the marginal distribution of surface area of tree component $i$ with height; and $\varphi_{S_{i}}(x \mid z)$ the marginal distribution of surface area of tree component $i$ across width at a given height $z$. The marginal distribution of surface area with height is used to calculate the relative surface area in a horizontal layer with respect to an entire tree (the simple integral term in function (1)), and can be found by measuring the vegetative surface area of each tree component layer by layer with height. The marginal distribution of surface area across width at a given height is used to calculate the relative surface area in a grid cell with respect to the layer (the double integral term in function (1)), and can be determined by measuring the vegetative surface area of each tree component section by section across the width dimension within a layer.

The working function for cubic density is given by

$$
\begin{aligned}
\beta_{C}(D, h, x, y, z) & \\
= & \frac{1}{\Delta x \Delta y \Delta z} \sum_{i=1}^{4} V_{i}(D, h)\left[\int_{z-0.5 \Delta z}^{z+0.5 \Delta z} \psi_{V_{i}}\left(z^{\prime}\right) \mathrm{d} z^{\prime}\right] \\
& \times\left[\frac{1}{\Delta z} \int_{z-0.5 \Delta z}^{z+0.5 \Delta z} \int_{x-0.5 \Delta x}^{x+0.5 \Delta x} \varphi_{V_{i}}\left(x^{\prime} \mid z^{\prime}\right) \mathrm{d} x^{\prime} \mathrm{d} z^{\prime}\right]
\end{aligned}
$$

The symbols in this function are defined analogous to those in function (1) with $V$ indicating volume. To estimate the 3D aerodynamic structure of a tree shelterbelt requires developing the equations for each tree component in functions (1) and (2).

\section{Data collection}

Two, double row, 31-year-old shelterbelts, composed of green ash, eastern red cedar (Juniperus virginiana L.) and Austrian pine (Pinus nigra Arnold), located at the University of Nebraska Agricultural Research and Development Center near Mead, NE $\left(41^{\circ} 29^{\prime} \mathrm{N}, 96^{\circ} 30^{\prime} \mathrm{W}\right.$, and $354 \mathrm{~m}$ above mean sea level) were sampled. One row consisted of alternating green ash and eastern red cedar. The other row consisted of alternating pairs of green ash and Austrian pine. Within row spacing was $2 \mathrm{~m}$ and between row spacing was $4 \mathrm{~m}$. The basal area ratio of the three species was 7.6 (green ash):1.5 (Austrian pine):0.9 (eastern red cedar). Green ash averaged $11.5 \mathrm{~m}$ in height, ranging from 5.0 to $14.0 \mathrm{~m}$, and $24.0 \mathrm{~cm}$ in $\mathrm{DBH}$, ranging from 6.7 to $38.0 \mathrm{~cm}$. The data on green ash structure was then used to develop a hypothetical shelterbelt consisting entirely of green ash with a planting pattern similar to the measured shelterbelt.

Eighteen green ash trees were destructively sampled in 1996 and 1997. In order to describe the marginal distributions of surface area and volume with height, four of the 18 trees were separated into simple non-branched segments and individual leaves by $1 \mathrm{~m}$ 
horizontal layers for measurement. The remaining 14 trees were separated into simple non-branched segments and individual leaves for measurement. Each trunk was divided into $1 \mathrm{~m}$ sections, and the middle diameter of each section was measured to calculate surface area and volume (Husch et al., 1982; Bai et al., 1987). By measuring the length $\left(l_{B}\right)$ and middle diameter $\left(D_{m}\right)$, the surface area $\left(S_{S B}\right)$ and volume $\left(V_{S B}\right)$ of a single branch were determined using

$S_{S B}=\pi f_{S} D_{m} l_{B}$

where $f_{S}$ is the branch surface area adjustment factor, i.e., a surface area ratio of a single branch to a cylinder which has the same middle diameter and length as the branch, and

$V_{S B}=\frac{1}{4} \pi f_{V} D_{m}^{2} l_{B}$

where $f_{V}$ is the branch volume adjustment factor, i.e., volume ratio of a single branch to a cylinder which has the same middle diameter and length as the branch. Both surface area and volume adjustment factors were estimated by sectionally measuring 345 single branches of different sizes, each of which was divided into at least five sections. The measured surface area and volume adjustment factors in two branch size (middle cross-sectional area $\times$ length) classes had different means and standard deviations. Both measured factors were, however, independent of branch size within a class (Zhou, 1999). The branch surface area adjustment factor was $1.003 \pm 0.014$ for branch size $\leq 0.1 \mathrm{dm}^{3}$, and $0.990 \pm 0.013$ for branch size $>0.1 \mathrm{dm}^{3}$. The branch volume adjustment factor was $1.049 \pm 0.032$ for branch size $\leq 0.1 \mathrm{dm}^{3}$, and $1.259 \pm 0.039$ for branch size $>0.1 \mathrm{dm}^{3}$.

The surface areas and volumes of leaves and seeds were estimated indirectly from dry weight using specific surface area (Davies and Benecke, 1980) and specific volume. To determine the specific surface areas of samples of both tree components, the surface areas were measured using the LI-3100 Area Meter (LI-COR), and the dry volumes were measured using the displacement method (Ronco, 1969). The surface areas of leaf and seed samples were computed by doubling the meter reading, assuming that neither had significant thickness. Dry weights of leaves and seeds were determined by drying samples to constant weight in a forced-air oven at $65^{\circ} \mathrm{C}$.
The measured data were used to estimate the parameters in each equation with the Marquardt method in the NLIN Procedure of SAS ${ }^{\odot}$ (SAS Institute, 1990).

\section{Equation development}

\subsection{Surface area and volume and their marginal distributions with height}

\subsubsection{Trunk}

Trunk surface area and volume and their marginal distributions with height can be predicted from DBH and/or height if a trunk form equation describing the radius at a given height $[r(D, h, z)]$ can be defined. A number of possible form equations exist (Beher, 1927; Husch et al., 1982; Bai et al., 1987). The form equation with the best fit was a third order polynomial:

$r(D, h, z)=D \sum_{j=1}^{3} a_{r j}\left(1-\frac{z}{h}\right)^{j}, \quad 0 \leq z \leq h$

where $a_{r j}(j=1,2$, and 3$)$ is a parameter. The 251 measured radii of the 18 green ash trunks at different heights were fitted to this equation with 95.0\% PVE (percentage of variance explained by regression), and $P<0.001$. The $95 \%$ confidence interval of $a_{r 2}$ included zero so the second order term was dropped. To make this equation have a better fit, it was modified to $r_{m}(D, h, z)$ by adding an exponential parameter on $D$ and refitting to the measured data

$$
\begin{aligned}
& r_{m}(D, h, z) \\
& =D^{0.8645}\left[0.7205\left(1-\frac{z}{h}\right)+0.2414\left(1-\frac{z}{h}\right)^{3}\right] \\
& 0 \leq z \leq h, \text { PVE }=97.3 \%, P<0.001
\end{aligned}
$$

Using this form equation, equations for trunk surface area, volume and their marginal distributions with height can be derived and fitted to the data (Table 1).

\subsubsection{Branches}

Predicting the branch volume and surface area of an entire tree using easily measured parameters is highly desirable. While the measured branch volume and surface area of an entire tree can be fitted to numerous equations, an equation capable of describing the intrinsic relationship of branch volume or surface area 
Table 1

Equation set for estimating the $3 \mathrm{D}$ aerodynamic structure of a green ash shelterbelt ${ }^{\mathrm{a}, \mathrm{b}}$

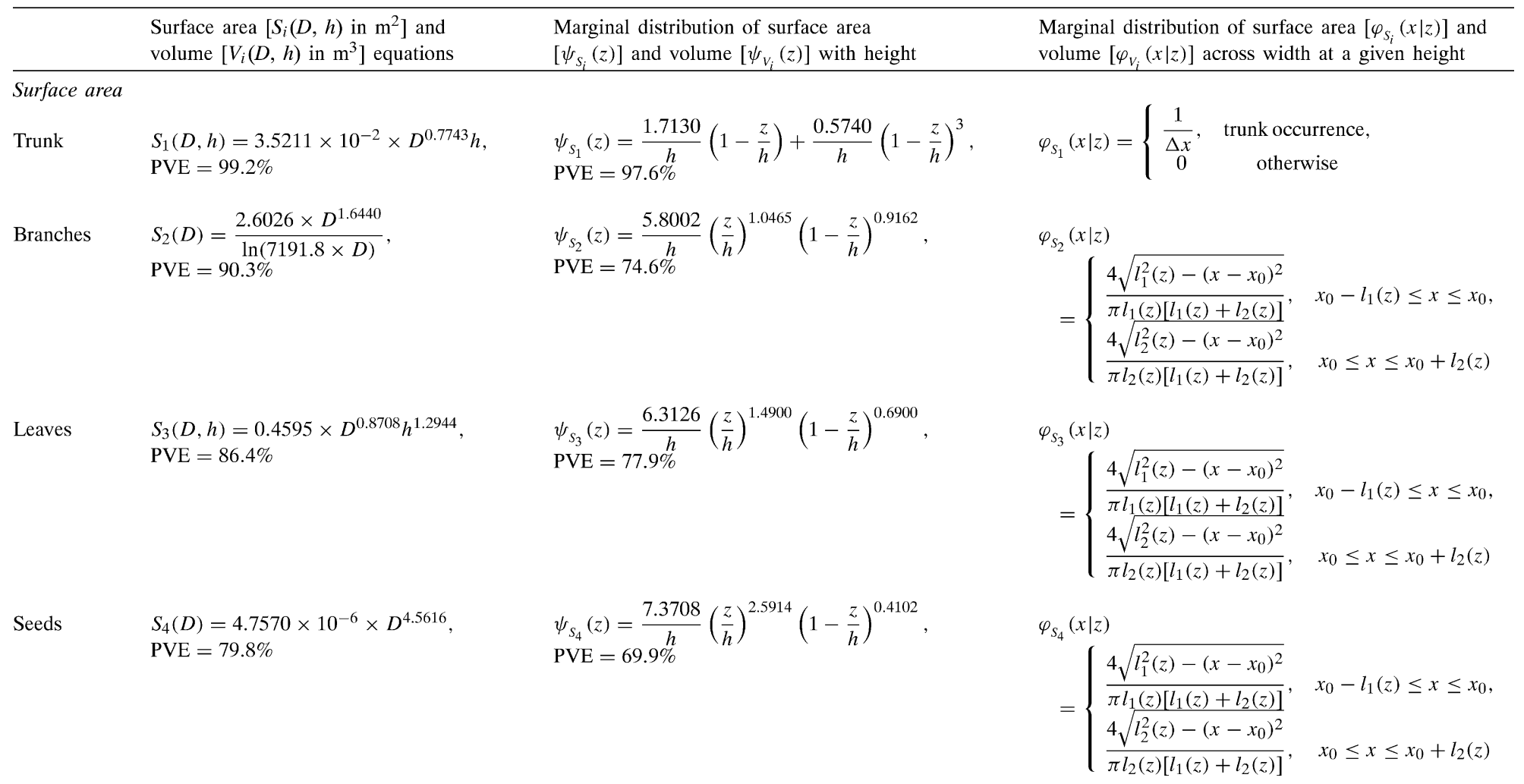


Volume

\section{Trunk}

$V_{1}(D, h)=1.4068 \times 10^{-4} \times D^{1.5509} h$,

$$
\mathrm{PVE}=99.4 \%
$$

Branches

$$
\begin{aligned}
& V_{2}(D)=\frac{2.1044 \times 10^{-3} \times D^{2.2468}}{\ln (7191.8 \times D)}, \\
& \text { PVE }=94.5 \%
\end{aligned}
$$

$V_{3}(D, h)=3.3891 \times 10^{-5} \times D^{0.8351} h^{1.4751}$,

$$
\mathrm{PVE}=85.7 \%
$$

$V_{4}(D)=2.1200 \times 10^{-10} \times D^{5.2149}$, $\mathrm{PVE}=83.2 \%$

$$
\mathrm{PVE}=83.2 \%
$$

a $D(\mathrm{~cm})$ is the diameter of tree trunk at height of $1.37 \mathrm{~m}, h(\mathrm{~m})$ the tree height, $l_{1}(z)(\mathrm{m})$ and $l_{2}(z)(\mathrm{m})$ are the tree crown diameters at a given height of $z(\mathrm{sec}$ Fig. $2 \mathrm{~A})$, PVE the percentage of variance explained by regression, $x(\mathrm{~m})$ and $z(\mathrm{~m})$ the coordinates across width and with height, $x_{0}(\mathrm{~m})$ the coordinate of vertical axis of trunk across width, and $\Delta x(\mathrm{~m})$ the dimension of a grid cell across width (see Fig. 1).

${ }^{\mathrm{b}} P \leq 0.001$ for all regressions.

$$
\begin{array}{ll}
\psi_{V_{1}}(z)=\left[\frac{1.4384}{\sqrt{h}}\left(1-\frac{z}{h}\right)+\frac{0.4819}{\sqrt{h}}\left(1-\frac{z}{h}\right)^{3}\right]^{2}, & \varphi_{V_{1}}(x \mid z) \text { is the same as } \varphi_{S_{1}}(x \mid z) \\
\operatorname{PVE}=95.9 \% & \varphi_{V_{2}}(x \mid z) \text { is the same as } \varphi_{S_{2}}(x \mid z) \\
\psi_{V_{2}}(z)=\frac{10.9733}{h}\left(\frac{z}{h}\right)^{1.3356}\left(1-\frac{z}{h}\right)^{1.4007}, & \varphi_{V_{3}}(x \mid z) \text { is the same as } \varphi_{S_{3}}(x \mid z)
\end{array}
$$

$\varphi_{V_{4}}(x \mid z)$ is the same as $\varphi_{S_{4}}(x \mid z)$

$\psi_{V_{4}}(z)$ is the same as $\psi_{S_{4}}(z)$ 
to $\mathrm{DBH}$ and/or height is preferred. The branch volume of an entire tree $\left(V_{2}\right)$ is

$V_{2}=\frac{\pi}{4} \sum_{k=1}^{n} N_{k} f_{V} D_{m k}^{2} l_{B k}$

where $n$ is the number of branch groups. In the $k$ th $(k=1,2, \ldots, n)$ group, $N_{k}$ denotes the number of branches; $D_{m k}$ is the middle diameter; and $l_{B k}$ the length. The branch volume of an entire tree can then be associated with its DBH and/or height if the variables on the right-hand side of this equation are expressed in terms of DBH and/or height. Using $v_{k}$ to denote $\pi D_{m k}^{2} l_{B k} / 4$, Eq. (7) gives

$V_{2}=f_{V} \sum_{k=1}^{n} N_{k} v_{k}=f_{V} v_{\max } \sum_{k=1}^{n} N_{k} r_{V k}$

where $v_{\max }$ is the maximum of $v_{k}$, and $r_{V k}$ the relative volume of a branch in the $k$ th group $\left(v_{k} / v_{\max }\right)$. If the total number of branches of an entire tree is denoted by $N$ and the probability density function of branch numbers with respect to the relative branch volume is represented by $\psi_{N}\left(r_{V}\right)$, where $r_{V}$ is the relative volume, this equation becomes

$$
\begin{aligned}
V_{2} & \approx f_{V} v_{\max } N \sum_{k=1}^{n} \Delta r_{V k} \psi_{N}\left(r_{V k}\right) r_{V k} \\
& \approx f_{V} v_{\max } N \int_{r_{\min }}^{1} \psi_{N}\left(r_{V}\right) r_{V} \mathrm{~d} r_{V}
\end{aligned}
$$

where $\Delta r_{V k}=r_{V(k+1)}-r_{V(k)}$ and $r_{\min }$ is the relative volume of the smallest branch. In this equation, $f_{V}$ is a constant. The volumes of the largest branches from each of the 18 green ash trees $\left[v_{\max }(D)\right]$ showed an allometric relationship to their $\mathrm{DBH}$ :

$v_{\max }(D)=9.9496 \times 10^{-6} \times D^{2.5899}$,

$\mathrm{PVE}=91.2 \%, P<0.001$

According to the fractal bifurcation of a tree (Borchert and Slade, 1981; Stewart, 1988; Zeide, 1998), the number of branches of an entire tree $[N(D)]$ can be related to $\mathrm{DBH}$ and fitted to the measured data giving

$$
N(D)=\frac{741.12 \times D^{1.4678}}{\ln (7191.8 \times D)},
$$$$
\mathrm{PVE}=94.8 \%, P<0.001
$$

A property of the probability density function (Bain and Engelhardt, 1992; Hogg and Craig, 1995) gives

$\int_{r_{\min }}^{1} \psi_{N}\left(r_{V}\right) \mathrm{d} r_{V}=1$

Because $r_{V}$ is less than or equal to 1 but positive. The definite integral term in Eq. (9) is a constant greater than zero and less than unity.

Substituting Eqs. (10) and (11) into Eq. (9), the branch volume of an entire tree $\left[V_{2}(D)\right]$ can be related to DBH and fitted to the measured data (Table 1). Following the same procedure, the branch surface area of an entire tree $\left[S_{2}(D)\right]$ is developed (Table 1).

According to the pattern of the data, the measured marginal distribution densities of branch surface area and volume with height were fitted to the beta distribution (Hogg and Craig, 1995) (Table 1).

\subsubsection{Leaves}

Using the typical shape of a green ash crown described by Hightshoe (1988) and the allometric relationship of crown radius to DBH (Bai et al., 1987), the crown radius of a green ash at a given height $[R(D, h$, z)] may be approximated by

$$
R(D, h, z)=a_{R 1} D^{a_{R 2}} z^{a_{R 3}}(h-z)^{a_{R 4}}, \quad 0 \leq z \leq h
$$

where $a_{R 1}, a_{R 2}, a_{R 3}$ and $a_{R 4}$ are parameters. Based on our personal observation, the leaves of a green ash are assumed to be approximately uniformly distributed within the envelope of its crown. By integrating leaf surface area and volume per unit canopy volume in the region bounded by the curve of Eq. (13), respectively, the equations for leaf surface area and volume can be derived and fitted to the data (Table 1). According to the crown shape described by Eq. (13), the marginal distributions of leaf surface area and volume with height also can be derived and fitted to the data (Table 1). The developed equation for the marginal distribution of leaf surface area with height is the same as that of leaf volume with height. The measured distribution densities of leaf surface areas were consistent with those of leaf volumes. Because both leaf surface area and volume are proportional to leaf weight, their relative distribution must be the same. 


\subsubsection{Seeds}

Of the 18 measured trees, eight were female, and had seeds. Seed surface area and volume are a minor part of the shelterbelt structure representing only $2.79 \%$ of the tree surface area and $0.50 \%$ of the tree volume (Zhou, 1999). For simplicity, the seed surface area and volume of an entire tree were expressed as an allometric relationship to DBH $\left[S_{4}(D)\right.$ and $V_{4}(D)$ ]. Similar to the leaves, the marginal distributions of seed surface area and volume with height are the same and expressed as a beta distribution. These equations were fitted to the measured data (Table 1).

\subsection{Marginal distributions of surface area and volume across width at a given height}

By referencing Fig. 2A, the marginal distribution of trunk surface area and volume across width at a given height can be visually defined as the same function form shown in Table 1.

The marginal distribution of surface area and volume across width at a given height for the other three components can be determined if their surface area and volume are measured horizontally section by section within a layer for all layers. Such measurements, however, are not available at this time. Alternatively, these distributions may be approximated according to green ash architecture. Assuming that the projection of a tree crown at any given height $(z)$ onto the ground is an ellipsoid jointly composed of two half ellipsoids (Fig. 2A) and assuming that the branches, leaves and seeds in a layer are uniformly distributed within the outline of the ellipsoid, the marginal distributions of their surface area and volume across width at a given height can be derived (Table 1). Because of the second assumption above, the derived marginal distributions of surface area are the same for these three tree components, and the derived marginal distributions for their surface areas are the same as those for their volumes. The curves of this marginal distribution at three different heights are illustrated in Fig. 2B. Using the derived marginal distribution, the relative surface areas across width for each discrete grid cell at the three heights were calculated as an example and represent the areas under the curves in Fig. 2B.

\section{Results}

All the equations in functions (1) and (2) have been developed and are summarized in Table 1 . The equations for a seed component are only applicable to female trees. Before using these equations, the resolution for the structural description was determined by referencing the measured tree height and spacings between trees and rows in the shelterbelt. The resulting resolution is shown in Fig. 1.

The surface area for each tree component in function (1) was estimated by substituting DBH and/or height into the corresponding surface area equation. The relative surface area of each tree component in a horizontal layer with respect to an entire tree in function (1) was estimated by substituting height into the corresponding marginal distribution of surface area with height. The relative vegetative surface area for each tree component in a grid cell with respect to the horizontal layer in function (1) was estimated using the marginal distribution of surface area across width at a given height. To use this marginal distribution, the spacings between trees and rows in the shelterbelt, and the distances from characteristic points of the shelterbelt canopy envelope (labeled by "*" in Fig. 2A) to the trunk and the corresponding heights of these points were measured for determination of the crown diameters across width at a given height $\left[l_{1}(z)\right.$ and $\left.l_{2}(z)\right]$. Substituting these into function (1), the vegetative surface area densities in all grid cells (Fig. 1) were estimated. Using the same procedure, the cubic densities in these grid cells were also estimated. As a result, the $3 \mathrm{D}$ aerodynamic structure of the green ash shelterbelt is described.

Unfortunately, current numerical simulations are unable to utilize a detailed description of structure along the length dimension due to computation demands. Consequently, the boundary-layer flows near a shelterbelt have been numerically simulated only in the width-height domain (Wilson, 1985; Wang and Takle, 1997; Patton et al., 1998). As a result, the average structure over the length dimension needs to be estimated for use in current numerical simulations.

In one of the sampled shelterbelts, there were 72 green ash trees, 35 in the north row and 37 in the south row. Using the procedure above, vegetative surface area densities and cubic densities for each of the 


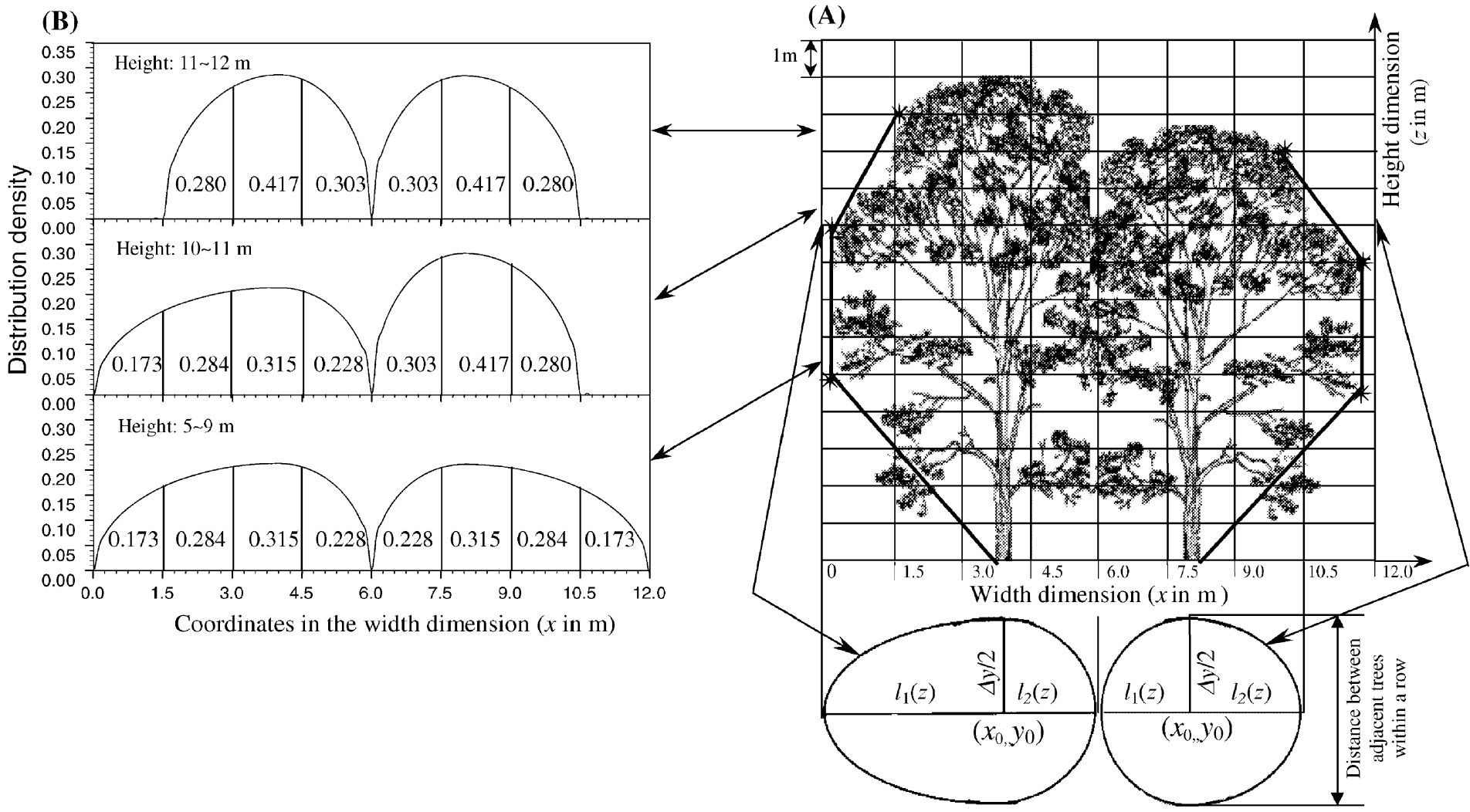

Fig. 2. Illustration of the marginal distribution of surface areas across the width dimension at a given height for trunk, branches, leaves and seeds: (A) projection of the tree crown at a height of $9 \mathrm{~m}$ onto the ground; (B) the marginal distribution of surface area across the width dimension at three heights for branches, leaves and seeds. (Note: the marginal distribution for volume is assumed to be the same.) 
Table 2

Estimates of the average vegetative surface area densities $\left(\mathrm{m}^{2} \mathrm{~m}^{-3}\right)$ of a green ash shelterbelt over the length dimension (the cells correspond to the grid cells in Fig. 1A)

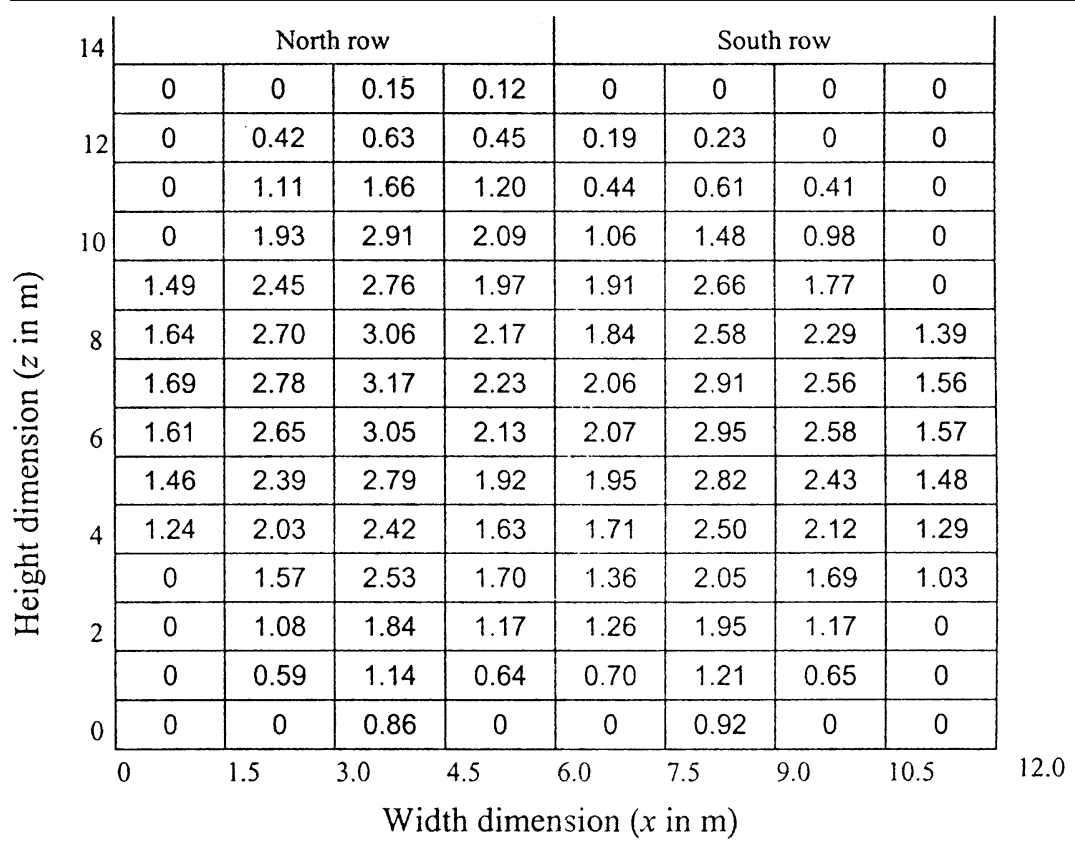

Table 3

Estimates of the average cubic densities $\left(\mathrm{m}^{3} \mathrm{~m}^{-3}\right)$ of a green ash shelterbelt over the length dimension (the cells correspond to the grid cells in Fig. 1A)

\begin{tabular}{|c|c|c|c|c|c|c|c|c|}
\hline \multirow{2}{*}{14} & \multicolumn{4}{|c|}{ North row } & \multicolumn{4}{|c|}{ South row } \\
\hline & 0 & 0 & 0.00005 & 0.00004 & 0 & 0 & 0 & 0 \\
\hline \multirow{4}{*}{$\begin{array}{l}\Xi \\
\Xi\end{array}$} & 0 & 0.00018 & 0.00028 & 0.00019 & 0.00007 & 0.00009 & 0 & 0 \\
\hline & 0 & 0.00058 & 0.00097 & 0.00063 & 0.00022 & 0.00033 & 0.00020 & 0 \\
\hline & 0 & 0.00123 & 0.00215 & 0.00133 & 0.00060 & 0.00094 & 0.00055 & 0 \\
\hline & 0.00118 & 0.00194 & 0.00287 & 0.00156 & 0.00128 & 0.00210 & 0.00118 & 0 \\
\hline \multirow{6}{*}{ 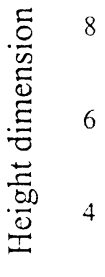 } & 0.00155 & 0.00255 & 0.00416 & 0.00204 & 0.00155 & 0.00290 & 0.00193 & 0.00118 \\
\hline & 0.00184 & 0.00302 & 0.00557 & 0.00242 & 0.00205 & 0.00427 & 0.00256 & 0.00156 \\
\hline & 0.00200 & 0.00328 & 0.00705 & 0.00263 & 0.00241 & 0.00574 & 0.00300 & 0.00183 \\
\hline & 0.00201 & 0.00330 & 0.00865 & 0.00265 & 0.00259 & 0.00735 & 0.00322 & 0.00196 \\
\hline & 0.00189 & 0.00310 & 0.01046 & 0.00249 & 0.00255 & 0.00913 & 0.00318 & 0.00194 \\
\hline & 0 & 0.00261 & 0.0135 & 0.00282 & 0.00227 & 0.01115 & 0.00283 & 0.00172 \\
\hline \multirow[t]{2}{*}{2} & 0 & 0.00195 & 0.01581 & 0.00211 & 0.00233 & 0.01435 & 0.00215 & 0 \\
\hline & 0 & 0.00114 & 0.01872 & 0.00123 & 0.00139 & 0.01712 & 0.00129 & 0 \\
\hline \multirow[t]{2}{*}{0} & 0 & 0 & 0.02330 & 0 & 0 & 0.02170 & 0 & 0 \\
\hline & 0 & 1.5 & 3.0 & 4.5 & 6.0 & 7.5 & 9.0 & 10.5 \\
\hline
\end{tabular}

Width dimension ( $x$ in $\mathrm{m})$ 
72 trees were estimated and averaged over the length dimension to give the vegetative surface area densities and cubic densities of the green ash shelterbelt (Tables 2 and 3).

\section{Discussion}

\subsection{Application of the estimated shelterbelt structure}

In the past, there were no field measurements available for the 3D structure of tree shelterbelts. As a result, the drag force term in the equations of motion was parameterized only using assumed vegetative surface area density for a numerical simulation of the boundary-layer flows near a hypothetical shelterbelt (Wilson and Mooney, 1997). The estimates of vegetative surface area density and cubic density in Tables 2 and 3 can now be incorporated into current turbulence models.

In addition, the magnitude of, and variation in vegetative surface area density and cubic density provide a reasonable reference for future numerical simulations. The vegetative surface area densities of a double row green ash shelterbelt ranged from 0.12 to $3.17 \mathrm{~m}^{2} \mathrm{~m}^{-3}$ (Table 2), and its cubic densities from 0.00004 to $0.02330 \mathrm{~m}^{3} \mathrm{~m}^{-3}$ (Table 3). Variation among the columns and rows in both tables shows the spatial variation across width, and with height.

\subsection{Aerodynamics of shelterbelt structure}

Gross (1987) used either cubic density or vegetative surface area density to parameterize the drag force term in the equations of motion for simulation of the wind flow within and around a single tree. If the ratio of vegetative surface area density to cubic density were spatially constant, or

$\frac{S_{\mathrm{AD}}\left(x_{1}, x_{2}, x_{3}\right)}{D_{\mathrm{C}}\left(x_{1}, x_{2}, x_{3}\right)}=\mathrm{constant}$

then the drag force term in the equations of motion could be parameterized by either structural descriptor, because the drag force term parameterized by vegetative surface area density is proportional to cubic density.

The vertical profiles of surface area and volume of the four tree components: trunk, branches, leaves and seeds in Fig. 3 reflect the average vertical distributions of surface area and volume of a whole shelterbelt rather than the individual tree. The non-uniformity of the vegetative surface area density and cubic density with height resulted from the vertical variation in vegetative surface area and volume. The ratio of total vegetative surface area in Fig. $3 \mathrm{~A}$ to the total volume in Fig. 3B at the same height dramatically increases with increasing height (Fig. 4), indicating that the ratio of vegetative surface density to cubic density is not constant.

The large variation in the ratio of vegetative surface area to volume suggests that neither vegetative surface area nor volume alone can represent the aerodynamic structure of a shelterbelt canopy. However, the small magnitude of cubic density $\left(0.00004-0.02330 \mathrm{~m}^{3} \mathrm{~m}^{-3}\right.$ in Table 3) suggests that vegetative surface area density alone can best describe the aerodynamic structure of a shelterbelt or forest canopy (Wang and Takle, 1997; Lee and Black, 1993), because maximum cubic density $\left(0.02330 \mathrm{~m}^{3} \mathrm{~m}^{-3}\right)$ is well below the limit of relative change in air volume $(0.05)$ when air flow can be considered as incompressible (Schlichting, 1979). The estimated structure can be used to test and compare the relative importance of vegetative surface area and volume on the aerodynamic influence of a shelterbelt.

\subsection{A method to estimate the $3 D$ aerodynamic structure of a shelterbelt}

All the equations in functions (1) and (2) were developed based on tree architecture. The marginal distributions of leaf surface with height follows a beta distribution, which agrees with other research using the beta distribution for generating vertical profiles of leaf area density of other tree species (Massman, 1982; Meyers et al., 1998). The marginal distributions of the surface area and volume of branches, leaves and seeds across width at a given height were derived by assuming that the surface area and volume of these three tree components within a layer are uniformly distributed (see Section 4.2). This assumption appears reasonable for leaves and seeds, but may have limitations for branches, because a branch tapers with distance from the trunk which may result in more branch surface area and volume closer to the trunk. 


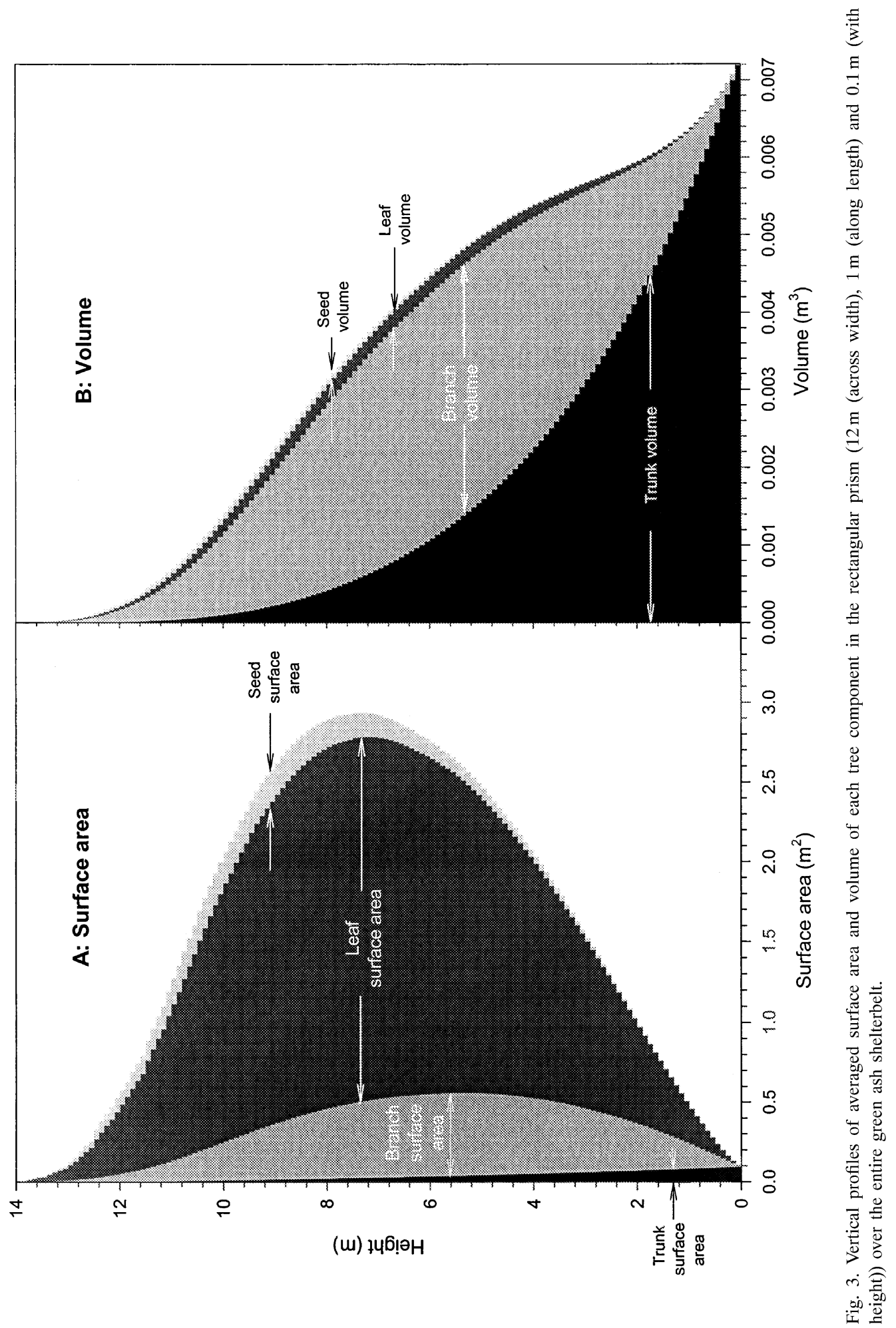




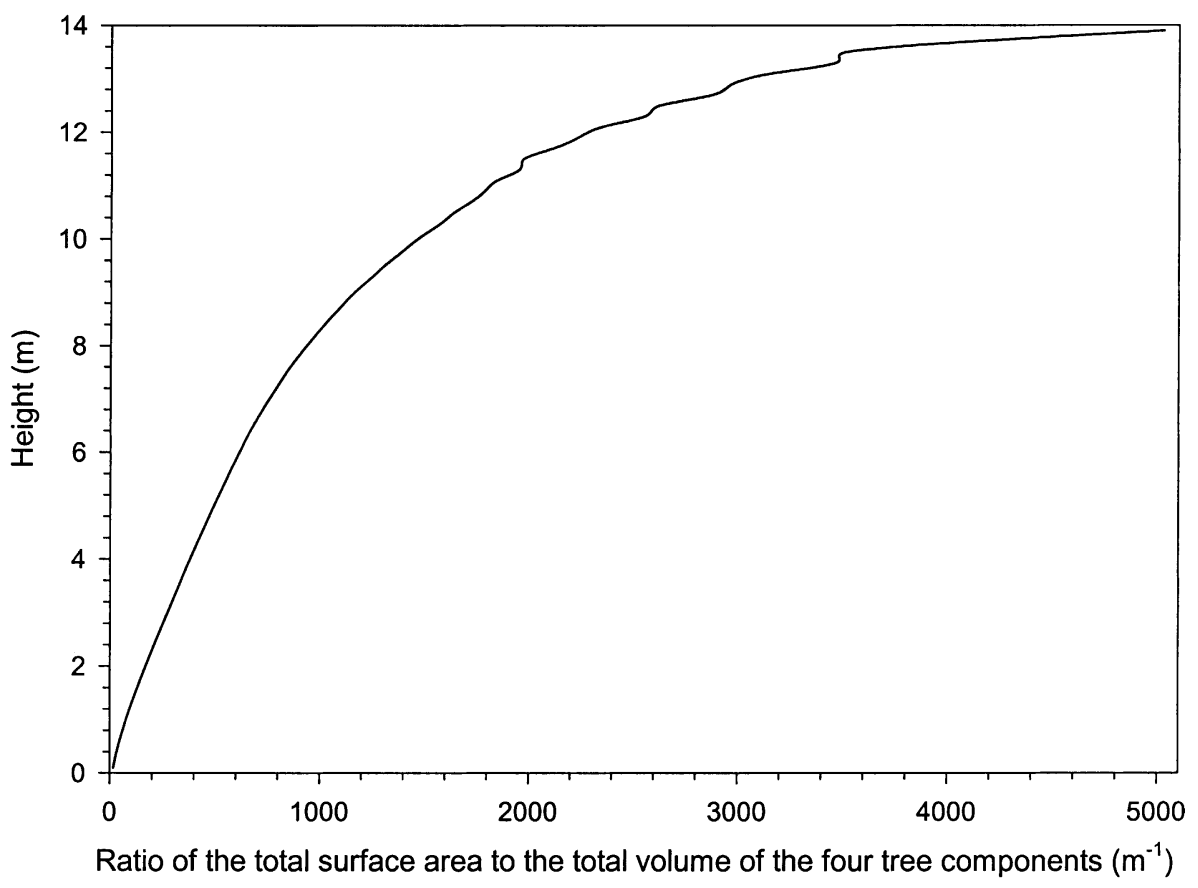

Fig. 4. Vertical profile of the ratio of the total surface area at a given height in Fig. 3A to the total volume at that height in Fig. 3B.

In this paper, the 3D aerodynamic structure was estimated for a 31-year-old green ash shelterbelt. The 3D structure of shelterbelts with different designs will be different. The method developed in this paper for describing the 3D structure is applicable to any type of a tree shelterbelt. However, this method is complicated, because it involves the development of the equations in functions (1) and (2). Consequently, it is necessary to develop an efficient indirect method to estimate 3D structure. This estimated structure becomes valuable, however, as a reference point of actual structure for the development of a more efficient indirect method.

Description of the 3D structure for a wide variety of shelterbelts will remain limited until an indirect method of estimating the structure becomes available. This limitation makes it difficult to predict the aerodynamic influences of tree shelterbelts with different designs. The equations in this paper are, however, directly applicable to shelterbelts with the same design. These equations also can be used to estimate the 3D structure of other green ash shelterbelts or of shelterbelts with species similar in architecture to those in the sampled shelterbelt. Using these equations, only
$\mathrm{DBH}$, tree height, planting pattern, spacing, and crown diameter as shown in Fig. 2A are required. However, tree sex also needs to be observed for an application of the equations for a seed component.

\section{Conclusion}

Our aim has been to develop a method to estimate the vegetative surface area density and cubic density of a tree shelterbelt in three dimensions, and to present the actual 3D aerodynamic structure of a green ash shelterbelt. Both vegetative surface area density and cubic density are estimated in three dimensions using the equations derived according to green ash architecture. The parameters in these equations are estimated using data measured in two dimensions.

The equations show that: (1) for trunk, leaves and seeds, the surface area and volume are exponential functions of DBH and/or height; (2) for branches, the surface area and volume are a ratio of an exponential function of DBH to a logarithmic function of $\mathrm{DBH}$; and (3) the marginal distributions of surface area and 
volume with height for the trunk are third and sixth order polynomials, and for branches, leaves and seeds are beta distributions.

The estimated 3D structure shows that spatial variation in vegetative surface area density and cubic density is large (Tables 2 and 3 and Figs. 3 and 4) and that the magnitude of cubic density is small (Table 3 ). The large variation in the 3D structure suggests that the assumption of uniform distribution of vegetative surface area for current simulations of turbulence flow through a shelterbelt canopy (Wang and Takle, 1997) may need to be re-evaluated. The small magnitude of cubic density supports the current assumption that simulation of turbulence through a shelterbelt or forest canopy can neglect vegetative volume (Lee and Black, 1993).

The estimated structure can be used to simulate the wind fields as influenced by actual structure of a tree shelterbelt, to test the aerodynamics of its different structural components, and to help us further understand the aerodynamics of overall shelterbelt structure. The developed equations can be used to estimate the $3 \mathrm{D}$ aerodynamic structure of green ash shelterbelts with similar design and other shelterbelts with similar species composition. The destructive measurements in this paper are labor intensive, and an efficient indirect method to estimate the 3D structure is needed. The estimated 3D structure provides, however, a valuable reference for development of this method.

\section{Acknowledgements}

This work has greatly benefited from the advice of Drs. Ellen T. Paparozzi, Shashi B. Verma and George E. Meyer, and additional review by Drs. Qi "Steve" $\mathrm{Hu}$, Michele M. Schoeneberger, R.A. Schmidt, and anonymous reviewers. Their suggestions substantially improved this paper. This research was supported by USDA/CSRS NRI Competitive Grants (Nos. 93-37101-8954 and 96-35209-892) and by the McIntyre-Stennis Forestry Research Program.

\section{References}

[1] Bai, Y.Q., Hao, W.K., Jiang, Y.Y., Lang, K.J., 1987. Forest Mensuration. Publishing House of Northeast Forestry University, 364 pp. (in Chinese).
[2] Bain, L.J., Engelhardt, M., 1992. Introduction to Probability and Mathematical Statistics, 2nd Edition. Duxbury Press, An Imprint of Wadsworth Publishing Company, Belmont, CA, $644 \mathrm{pp}$.

[3] Beher, C.E., 1927. Form-class taper curves and volume tables and their application. J. Agric. Res. 35, 673-744.

[4] Borchert, R., Slade, N.A., 1981. Bifurcation ratios and the adaptive geometry of trees. Bot. Gaz. 142, 394-401.

[5] Brandle, J.R., Hintz, D.L., Sturrock, J.W., 1988. Windbreak Technology. Elsevier, Amsterdam, 598 pp.

[6] Brandle, J.R., Zhou, X.H., Takle, E.S., 2002. The influence of three-dimensional structure of a tree shelterbelt on aerodynamic effectiveness. In: Land-use Management for the Future. Proceedings of the Sixth Conference on Agroforestry in North America, Hot Springs, AR, USA, June 12-16, 1999, in press.

[7] Cao, S.S., Lei, Q.D., Jiang, F.Q., 1981. Field determinations of the optimum porosity and cross-sectional shape of a shelterbelt. Bulletin of the Institute of Forestry and Pedology. Science Press, Beijing. Acad. Sin. 5, 9-19 (in Chinese with French abstract).

[8] Coulson, J.M., Richardson, J.F., Backhurst, J.R., Harker, J.H., 1978. Chemical Engineering, Vol. 2: Unit Operations, 3rd Edition. Pergamon Press, Oxford, 807 pp.

[9] Davies, C.E., Benecke, U., 1980. Fluidized bed coating of conifer needles with glass beads for determination of leaf surface area. For. Sci. 26, 29-32.

[10] Gandemer, J., 1979. Wind shelters. J. Ind. Aerodyn. 4, 371389.

[11] Gross, G., 1987. A numerical study of the air flow within and around a single tree. Boundary-Layer Meteorol. 40, 311-327.

[12] Hagen, L.J., Skidmore, E.L., Miller, P.L., Kipp, J.E., 1981. Simulation of effect of wind barriers on airflow. Trans. ASAE 24, 1002-1008.

[13] Heisler, G.M., DeWalle, D.R., 1988. Effects of windbreak structure on wind flow. Agric. Ecosyst. Environ. 22-23, 41-69.

[14] Hightshoe, G.L., 1988. Native Trees, Shrubs, and Vines for Urban and Rural America: A Plant Design Manual for Environmental Designers. Van Nostrand Reinhold, New York, 819 pp.

[15] Hogg, R.V., Craig, A.T., 1995. Introduction to Mathematical Statistics, 5th Edition. Prentice-Hall, Englewood Cliffs, NJ, $564 \mathrm{pp}$.

[16] Holland, M.R., Grace, J., Hedley, C.L., 1991a. Momentum absorption by dried-pea crops. I. Field measurements over and within varieties of differing leaf structure. Agric. For. Meteorol. 54, 67-79.

[17] Holland, M.R., Grace, J., Hedley, C.L., 1991b. Momentum absorption by dried-pea crops. II. Wind tunnel measurements of drag on isolated leaves and pods. Agric. For. Meteorol. $54,81-93$.

[18] Husch, B., Miller, C.I., Beers, T.W., 1982. Forest Mensuration. Wiley, New York, 402 pp.

[19] Lee, X., 2000. Air motion within and above forest vegetation in non-ideal conditions. For. Ecol. Manage. 135, 3-18.

[20] Lee, X., Black, T.A., 1993. Atmospheric turbulence within and above a Douglas-fir stand. Part II. Eddy fluxes of sensible heat and water vapor. Boundary-Layer Meteorol. 64, 369389. 
[21] Massman, W.J., 1982. Foliage distribution in old-growth coniferous tree canopies. Can. J. For. Res. 12, 10-17.

[22] Meyers, T.P., Finkelstein, P., Clarke, J., Ellestad, T.G., Sims, P.F., 1998. A multilayer model for inferring dry deposition using standard meteorological measurements. J. Geophys. Res. D 103 (17), 22645-22661.

[23] Patton, E.G., Shaw, R.H., Judd, M.J., Raupach, M.R., 1998. Large-eddy simulation of windbreak flow. Boundary-Layer Meteorol. 87, 275-306.

[24] Perera, M.D.A.E.S., 1981. Shelter behind two-dimensional solid and porous fences. J. Wind Eng. Ind. Aerodyn. 8, 93104.

[25] Radke, J.K., Hagstrom, R.T., 1974. Wind turbulence in a soybean field sheltered by four types of wind barriers. Agron. J. 66, 273-278.

[26] Ronco, F., 1969. Volumeter for estimating quantity of conifer foliage. USDA Forest Service Research Note RM-133, pp. $1-2$.

[27] SAS Institute, 1990. The NLIN Procedure. SAS/STAT ${ }^{\circledR}$ User's Guide, Version 6, Vol. 2, 4th Edition. SAS Institute, Inc., Cary, NC, pp. 1135-1194.

[28] Scheidegger, A.E., 1974. The Physics of Flow through Porous Media, 3rd Edition. University of Toronto Press, Toronto, $353 \mathrm{pp}$.

[29] Schlichting, H., 1979. Boundary-layer Theory, 7th Edition. McGraw-Hill, New York, 817 pp.

[30] Stewart, I., 1988. Irregular tricks of the trade. Nature 336, 289.
[31] Tabler, R.D., Veal, D.L., 1971. Effect of snow fence height on wind speed. Bull. Int. Assoc. Sci. Hydrol. 16, 49-56.

[32] Thom, A.S., 1971. Momentum absorption by vegetation. Quart. J. R. Meteorol. Soc. 97, 414-428.

[33] Wang, H., Takle, E.S., 1995. Numerical simulations of shelterbelt effects on wind direction. J. Appl. Meteorol. 34, 22062219.

[34] Wang, H., Takle, E.S., 1996. On three-dimensionality of shelterbelt structure and its influences on shelter effects. Boundary-Layer Meteorol. 79, 83-105.

[35] Wang, H., Takle, E.S., 1997. Momentum budget and shelter mechanism of boundary-layer flow near a shelterbelt. Boundary-Layer Meteorol. 82, 417-435.

[36] Wilson, J.D., 1985. Numerical studies of flow through a windbreak. J. Wind Eng. Ind. Aerodyn. 21, 119-154.

[37] Wilson, J.D., 1987. On the choice of a windbreak porosity profile. Boundary-Layer Meteorol. 38, 37-49.

[38] Wilson, J.D., Mooney, C.J., 1997. Comments on 'a numerical simulation of boundary-layer flows near shelterbelts' by H. Wang and E. Takle: Correspondence. Boundary-Layer Meteorol. 85, 137-149.

[39] Woodruff, N.P., Zingg, A.W., 1953. Wind tunnel studies of shelterbelt models. J. For. 51, 173-178.

[40] Zeide, B., 1998. Fractal analysis of foliage distribution in loblolly pine crowns. Can. J. For. Res. 28, 106-114.

[41] Zhou, X.H., 1999. On the three-dimensional aerodynamic structure of shelterbelts. Ph.D. Thesis. University of Nebraska, Lincoln, NE, 193 pp. 